\title{
Phylogeny of Gastrotricha: A Morphology-Based Framework of Gastrotrich Relationships
}

\author{
Rick Hochberg; Marianne K. Litvaitis \\ Biological Bulletin, Vol. 198, No. 2. (Apr., 2000), pp. 299-305.
}

Stable URL:

http://links.jstor.org/sici?sici=0006-3185\%28200004\%29198\%3A2\%3C299\%3APOGAMF\%3E2.0.CO\%3B2-X

Biological Bulletin is currently published by Marine Biological Laboratory.

Your use of the JSTOR archive indicates your acceptance of JSTOR's Terms and Conditions of Use, available at http://www.jstor.org/about/terms.html. JSTOR's Terms and Conditions of Use provides, in part, that unless you have obtained prior permission, you may not download an entire issue of a journal or multiple copies of articles, and you may use content in the JSTOR archive only for your personal, non-commercial use.

Please contact the publisher regarding any further use of this work. Publisher contact information may be obtained at http://www.jstor.org/journals/mbl.html.

Each copy of any part of a JSTOR transmission must contain the same copyright notice that appears on the screen or printed page of such transmission.

The JSTOR Archive is a trusted digital repository providing for long-term preservation and access to leading academic journals and scholarly literature from around the world. The Archive is supported by libraries, scholarly societies, publishers, and foundations. It is an initiative of JSTOR, a not-for-profit organization with a mission to help the scholarly community take advantage of advances in technology. For more information regarding JSTOR, please contact support@jstor.org. 


\title{
Phylogeny of Gastrotricha: a Morphology-Based Framework of Gastrotrich Relationships
}

\author{
RICK HOCHBERG* AND MARIANNE K. LITVAITIS \\ Department of Zoology and Center for Marine Biology, University of New Hampshire, \\ Durham, New Hampshire
}

\begin{abstract}
Currently, the phylum Gastrotricha is divided into the orders Macrodasyida and Chaetonotida, with the structure of the myoepithelial pharynx being an important distinguishing feature. Macrodasyida currently has six recognized families, and Chaetonotida comprises seven families. However, withingroup relationships are poorly understood. To arrive at a better understanding of gastrotrich systematics and phylogeny, we performed the first cladistic analysis of nearly all known gastrotrich genera using 71 morphological characters. Results suggest that the Gastrotricha is a monophyletic group (supported by $82 \%$ of bootstrap replications) with its most primitive taxa distributed among the families Dactylopodolidae and Neodasyidae. Monophyly of Macrodasyida and Chaetonotida was supported by $90 \%$ and $52 \%$ bootstrap replications, respectively. Within the Macrodasyida, the families Dactylopodolidae, Turbanellidae, Macrodasyidae, and Thaumastodermatidae all formed monophyletic clades. The families Planodasyidae and Lepidodasyidae were paraphyletic. Among the Chaetonotida, the marine family Xenotrichulidae was monophyletic, supported by $51 \%$ of bootstrap replications. A second clade containing all freshwater families was supported by $62 \%$ bootstrap values. However, Chaetonotidae were paraphyletic. Using this analysis as a framework, we now can explore possible patterns of evolution within it, and arrive at a consensus of the gastrotrich ground pattern. Moreover, in future molecular studies of metazoan phylogeny, we will be able to select gastrotrich species that are more appropriate representatives of the phylum.
\end{abstract}

\section{Introduction}

Gastrotrichs figure prominently in metazoan phylogeny because they share a suite of complex morphological char-

\footnotetext{
Received 16 July 1999; accepted 16 December 1999.

* To whom correspondence should be addressed. E-mail: rickh @ cisunix.unh.edu
}

acteristics with several other members of the Bilateria, including the Gnathostomulida and the Nematoda. But their microscopic size, their cryptic interstitial habitat, and the lack of fossil record have exacerbated the usual barriers to phylogenetic analysis. As a consequence, gastrotrichs are one of the least understood groups of aquatic invertebrate animals. Furthermore, the relationship of Gastrotricha to other extant metazoans is uncertain; results from recent molecular and morphological studies are in conflict (Winnepenninnckx et al., 1995; Littlewood et al., 1996; and Wallace et al., 1996). The currently accepted classification of the phylum Gastrotricha is based on morphological features (Hummon, 1982; Ruppert, 1988) and has two monophyletic orders, the Macrodasyida and Chaetonotida. Both orders are defined primarily by the structure of the myoepithelial pharynx (Ruppert, 1991), yet several other characteristics are important in the systematic classification of genera (Hummon, 1982; Ruppert, 1988; Ruppert, 1991) (Fig. 1).

Accepted morphological homologies supporting gastrotrich monophyly include the presence of unique, cuticlecovered duo-gland adhesive organs (Tyler and Rieger, 1980), a multilayered epicuticle (Rieger and Rieger, 1977), and cuticle-covered locomotory and sensory cilia (Rieger and Rieger, 1977). Other features often used to categorize gastrotrichs-cross-striated muscles (Travis, 1983), monociliated epidermis (Rieger, 1976), triradiate myoepithelial pharynx (Schmidt-Rhaesa et al., 1998), and bilayered nature of the cuticle (Schmidt-Rhaesa et al., 1998)-are plesiomorphies and, therefore, of limited systematic value. Of particular significance is the presence of a monociliated epidermis; this condition is considered a primitive trait among Metazoa (Rieger, 1976). A monociliated epidermis is found in several gastrotrich taxa (Rieger, 1976), including the Dactylopodolidae and Neodasyidae, arguing further for their basal positions within their respective orders. That the 


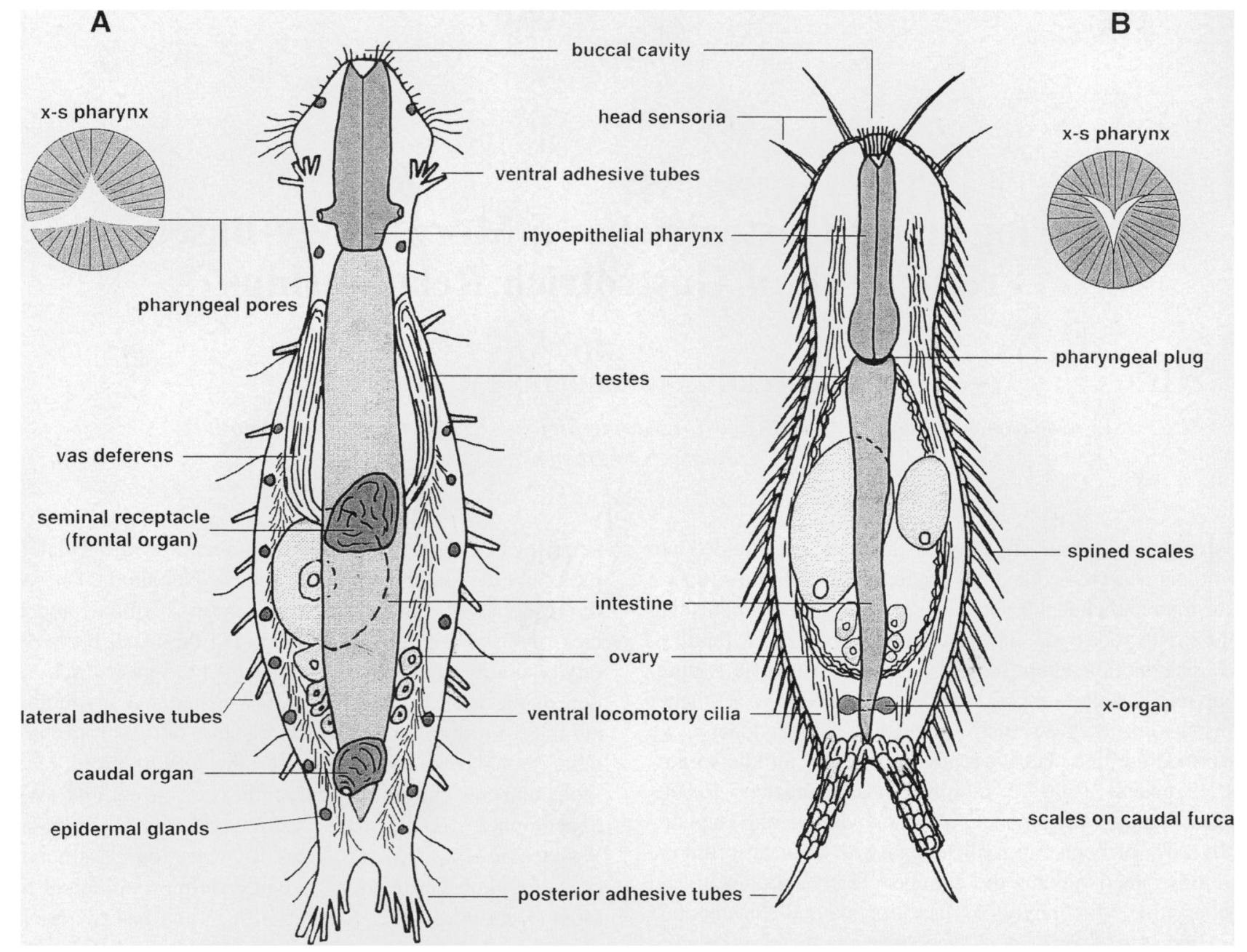

Figure 1. Schematic representation of (A) a macrodasyidan and (B) a chaetonotidan gastrotrich, showing characters separating the two orders. Cross-sections through pharynges show orientation of lumen and, in the macrodasyidan, the pharyngeal pores.

order Chaetonotida may be paraphyletic with respect to the phylum Nematoda, as suggested previously (Ruppert, 1982), is indicated by similarities in cuticular and pharyngeal ultrastructure (upright Y-shaped lumen, pharyngealintestinal valve), and pharyngeal innervation. Because of the complete absence of locomotory cilia in Nematoda, in conjunction with several other morphological characters, we agree with Lorenzen (1985) that the Nematoda is, at best, a sister taxon to the Gastrotricha.

\section{Materials and Methods}

We have analyzed relationships of nearly all known gastrotrich genera and evaluated them using parsimony analysis (PAUP 4.0*; Swofford, 1999). Eighty-one characters were used in the analysis, all unordered and unweighted (Table 1). For maximum parsimony, default settings included ACCTRAN, and multistate taxa were treated as uncertainties. Bootstrap options included 1000 replicates of 81 characters. Full heuristic searches were performed with starting trees obtained by stepwise random addition (10 replicates with two trees held at each step). Tree bisectionreconnection (TBR) branch swapping was performed with the MULTREES option to save all minimum-length trees. Two genera, Marinellina and Undula, were excluded from the analysis due to a lack of information. The Gnathostomulida and Nematoda were used as outgroups. The data matrix is available upon request from the first author.

\section{Results}

Our analysis resulted in a monophyletic Gastrotricha ( $82 \%$ bootstrap values). Within the phylum, Chaetonotida (supported by $52 \%$ of bootstrap replications) and Macrodasyida ( $90 \%$ of bootstrap replications) formed two monophyletic clades (Fig. 2). Although the Macrodasyida is a 
Table 1

Characters and character states used in parsimony analysis of Gastrotricha $(a=$ absent, $p=p r e s e n t)$

\section{Adhesive Tubes}

1. Cuticularized adhesive organs (tubes) $(0=\mathrm{a}, 1=\mathrm{p})$

2. Lateral adhesive tubes $(0=a, 1=p)$

3. Lateral adhesive organs indistinguishable, present as minute papillae $(0=a, 1=p)$

4. Ventrally placed anterior adhesive tubes $(0=a, 1=p)$

5. Anterior adhesive tubes in arc-like orientation $(0=a, 1=p)$

6. Anterior adhesive tubes on a mobile elevated base $(0=a, 1=p)$

7. Anterior adhesive tubes arranged together-as hands or clumps $(0=\mathrm{a}, 1=\mathrm{p})$

8. Posterior adhesive tubes $(0=\mathrm{a}, 1=\mathrm{p})$

9. Rounded caudal end bearing numerous adhesive tubes $(0=a, 1=p)$

10. Caudal end with tail-like extension bearing adhesive tubes $(0=\mathrm{a}, 1=\mathrm{p})$

11. Caudal end with elongate peduncle bearing adhesive tubes $(0=\mathrm{a}, 1=\mathrm{p})$

12. Caudal end is biramous/forked $(0=a, 1=p)$

13. Caudal end with only 2 adhesive tubules $(0=\mathrm{a}, 1=\mathrm{p})$

14. Proximal/distal separation of caudal adhesive tubules on elongate peduncle $(0=a, 1=p)$

15. Median caudal cone $(0=\mathrm{a}, 1=\mathrm{p})$

16. Caudal furca reduced to bilateral protuberances without adhesive tubes $(0=$ otherwise, $1=p)$

17. Ventrally placed extraordinary adhesive tubes as Seitenfüsschen $(0=a, 1=p)$

18. Seitenfüsschen as paired "brocha" tubules $(0=\mathrm{a}, 1=\mathrm{p})$

19. Seitenfüsschen as single "cirrata" tubules $(0=a, 1=p)$

\section{Alimentary System}

20. Condition of buccal capsule $(0=$ simple opening, $1=$ extended/folded/etc. $)$

21. Wide flaring buccal region $(0=\mathrm{a}, 1=\mathrm{p})$

22. Shape of myoepithelial pharyngeal lumen $(0=\mathrm{a}, 1=\mathrm{Y}$-shape, $2=$ upside-down $\mathrm{Y}$-shape $)$

23. Pharyngeal clefts $(0=\mathrm{a}, 1=\mathrm{p})$

24. Myoepithelial pharynx with cilia $(0=\mathrm{a}, 1=\mathrm{p})$

25. Microvilli penetrate pharynx exocuticle $(0=\mathrm{a}, 1=\mathrm{p})$

26. Pharyngeal foldings/plug $(0=\mathrm{a}, 1=\mathrm{p})$

27. Pharyngeal intrusions "teeth" $(0=\mathrm{a}, 1=\mathrm{p})$

28. Small pharyngeal pores $(0=a, 1=p)$

29. Ciliated gut epithelium $(0=a, 1=p)$

30. Distinct head enclosing most of the pharynx $(0=a, 1=p)$

\section{Body Wall}

31. Y-cells derived from longitudinal muscle block $(0=a, 1=p)$

32. Muscle striation pattern $(0=\mathrm{X}$-Striated, $1=$ Oblique $)$

33. Y-cell with myofilaments $(0=a, 1=p)$

34. Epidermal glands with band-like contents $(0=a, 1=p)$

35. Circular muscles $(0=\mathrm{p}, 1=\mathrm{a})$

36. Circular muscles absent from lateral body regions $(0=\mathrm{p}, 1=\mathrm{a})$

37. Dorsal epidermal glands $(0=$ absent, $1=$ present $)$

38. Body shape $(0=$ elongate, $1=$ ten-pin $)$

\section{Ciliation}

39. Epidermal ciliation $(0=$ monociliation, $1=$ multiciliation, $2=$ no ciliation $)$

40. One pair of short "cirri" $(0=a, 1=p)$

41. Ventral cilia and head sensoria modified as cirri $(0=a, 1=p)$

42. Construction of ventral and head cirri $(0=\mathrm{a}, 1=$ constructed as a singular unit, $2=$ each cilium with own cuticle)

43. Stylochaeta-type ciliation $(0=\mathrm{a}, 1=\mathrm{p})$

44. Ventral locomotory cilia restricted to head region as a distinct patch $(0=\mathrm{a}, 1=\mathrm{p})$

45. Ventral locomotory cilia present in 2 longitudinal rows $(0=\mathrm{a}, 1=\mathrm{p})$

46. Longitudinal rows of locomotory cilia abbreviated at mid-body region $(0=$ otherwise, $1=p)$

47. Cilia covered with cuticle $(0=a, 1=p)$

\section{Cuticle}

48. Scales constructed from basal cuticular layer-form solid endocuticular thickenings $(0=a, 1=p)$

49. Cuticular hooks/ancres (triancres, tetrancres, pentancres) $(0=\mathrm{a}, 1=\mathrm{p})$

50. Spines sculpted from surface zone of basal cuticular layer (not originating from flat scales) $(0=a, 1=p)$

51. Keeled scales derived from surface-zone of basal cuticular layer $(0=a, 1=p)$

52. Ventrolateral hydrofoil scales derived from surface-zone of basal cuticular layer $(0=a, 1=p)$ 
Table 1 (Continued)

53. Surface zone (of basal layer) spines present in groups $(0=a, 1=p)$

54. Surface-zone (of basal layer) scales $(0=a, 1=p)$

55. Surface-zone (of basal layer) scales lacking stalk and endplate $(0=a, 1=p)$

56. Surface-zone (of basal layer) scales in ventral interciliary field $(0=\mathrm{a}, 1=\mathrm{p})$

57. Surface-zone (of basal layer) scales in ventral interciliary field reduced to terminal field $(0=a, 1=p)$

58. Elongate scale-covered furca $(0=a, l=p)$

59. Head plates $(0=a, 1=p)$

\section{Nervous System/Sense Organs}

60. At least one pair of "soft, palp-like organs" on head $(0=a, 1=p)$

61. Club-shaped tentacles on head $(0=a, 1=p)$

62. Posterior nerve cords leaving circumpharyngeal ganglion $(0=$ multiple, $1=2$ total $)$

63. Cephalic chemoreceptors present as piston pits, pestles, cones or palps $(0=a, 1=p)$

64. Single pair of posterior head cones $(0=a, 1=p)$

65. Number of longitudinal tracts of pharyngeal nerves $(0=>3$ nerves, $1=3$ nerves $)$

\section{Reproductive System}

66. Paired ova mature in anterior to posterior direction $(0=a, 1=p)$

67. Sperm ducts join caudal organ $(0=a, 1=p)$

68. Seminal receptacle (frontal organ) $(0=a, 1=p)$

69. Caudal organ (penis) $(0=a, l=p)$

70. Complex frontal and caudal organs without tissue connection $(0=$ connection present, $1=$ connection absent, $2=$ not applicable $)$

71. Rosette organ $(0=a, 1=p)$

72. Paired testis $(0=$ otherwise, $1=p)$

73. Reduced left testis-single right testis only $(0=$ otherwise, $1=p)$

74. Reflexed vas deferens $(0=a, 1=p)$

75. Lumen of caudal and frontal organs continuous $(0=a, 1=p)$

76. Parthenogenesis $(0=a, 1=p)$

77. U-shaped gonad with caudal anastomosis $(0=\mathrm{a}, 1=\mathrm{p})$

78. Vas deferentia $(0=$ elongate, $1=$ reduced/absent $)$

79. Testes present as bilateral packets in post-parthenogenetic phase $(0=$ testes otherwise, $1=\mathrm{p}, 2=$ no testes $)$

80. $\mathrm{X}$-organ $(0=\mathrm{a}, 1=\mathrm{p})$

81. Condition of vas deferentia $(0=\mathrm{a}, 1=$ separate, paired or unpaired, $2=$ paired and fused)

highly heterogeneous group defined primarily by pharyngeal structure (Ruppert, 1991), the presence of groups of adhesive tubules (Hummon, 1982; Ruppert, 1988), and curious reproductive organs (Ruppert and Shaw, 1977; Ruppert, 1978), our analysis confirmed several monophyletic families within the order (Fig. 2). In fact, characters of the latter two organ systems substantiate monophyly of the two ecologically most diverse families, the Turbanellidae and Thaumastodermatidae (Fig. 2). These two families occur in nearly all marine environments at all depths, inhabit a wide array of sand types, and are probably among the most ubiquitous and successful groups of interstitial animals. As noted previously (Ruppert, 1988), the Lepidodasyidae is an unnatural taxon difficult to define on current morphological criteria. Our analysis found a paraphyletic Lepidodasyidae with some genera clustering with other families, although with low bootstrap values (Fig. 2). The monophyletic Dactylopodolidae (95\% bootstrap values) is affirmed as the most primitive macrodasyidan family, with retention of several plesiomorphic traits including epidermal monociliation, alimentary canal ciliation, cross-striated muscles, and separate multiple nerve cords in some genera (Fig. 2). Additional research on this family, in particular the relatively unknown Dendrodasys and Dendropodola, should further elucidate the ground pattern for the Gastrotricha.

Bootstrap values advocating a monophyletic Chaetonotida are relatively strong (52\%), and values for the monophyly of the suborder Paucitubulatina are even more robust (93\%) (Fig. 2). All chaetonotidans are largely defined by the configuration of the pharyngeal lumen (upright Y-shaped) and the absence of pharyngeal pores. But often, body-shape ("ten-pin") and the absence of anterior or lateral adhesive tubules are the most easily seen diagnostic characters. The monogeneric Multitubulatina, however, contains an anomalous vermiform Neodasys that shares traits with both Macrodasyida and Paucitubulatina. However, unlike all other members of the Chaetonotida, Neodasys is highly elongate and in possession of some potentially plesiomorphic characteristics: hermaphroditic gonads, complex reproductive organs, monociliated epidermis, smooth cuticle, and numerous adhesive tubules (Ruppert, 1991). Furthermore, the adhesive organ of Neodasys lacks a releaser gland (Tyler $e t$ 


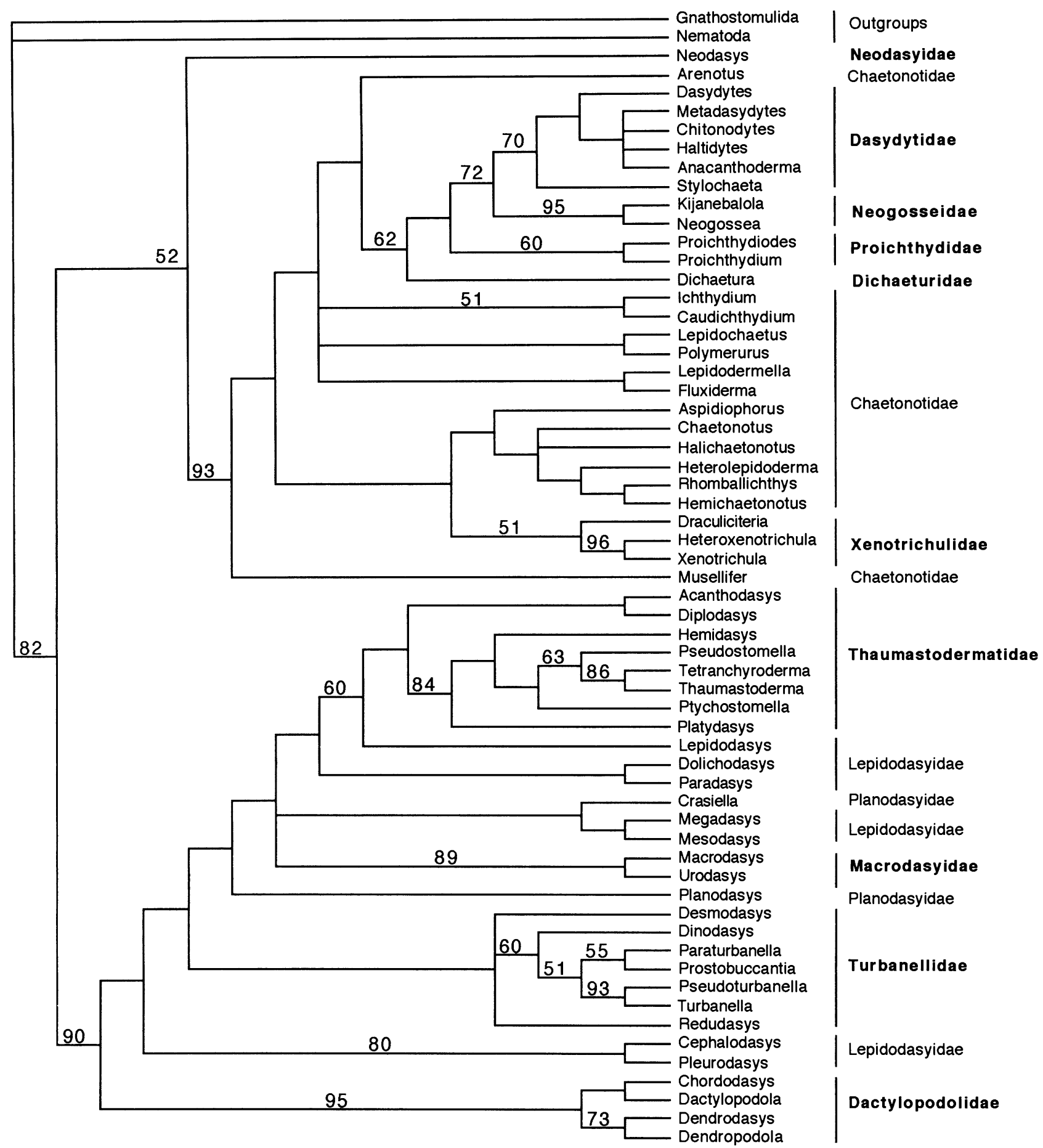

Figure 2. Consensus tree ( $50 \%$ Majority-Rule) of 59 gastrotrich genera. Tree length $=175$ steps; $\mathrm{CI}=$ $0.503, \mathrm{RC}=0.450$. Numbers at nodes represent percentages of 1000 bootstrap replications. Families indicated by bold type are monophyletic.

al., 1980). The presence of only one gland type in the adhesive organ is interpreted as a plesiomorphy when viewed in combination with the retention of other primitive traits (Tyler et al., 1980). Still, the presence of duogland adhesive organs in all Gastrotricha has not been confirmed, and it remains to be seen whether the presence of only a single gland is actually the "primitive" condition or is secondarily derived.

Within the Paucitubulatina, the largest and structurally most diverse family - the Chaetonotidae-appears to be paraphyletic (Fig. 2). This highly speciose taxon $(>250$ spp.) is extremely heterogeneous with respect to cuticular 
armature, habitat type, and reproductive anatomy. The family is presumed to have evolved in the freshwater benthos, radiating into the marine environment secondarily (Kisielewski, 1990). Yet, the existence of a very basal marine genus, Musellifer, might also argue for a marine origin. Resolution of this vastly diverse taxon will undoubtedly improve with greater attention to its reproductive anatomy (presence of hermaphroditic organs is unknown for many genera; the homology of the X-organ is in question) and the complex microstructure of both scales and spines.

Still, several important monophyletic groupings were confirmed within the Chaetonotida, including the entirely freshwater Dasydytidae, Neogosseidae, and Proichthydidae (Fig. 2). Our analysis thus confirmed a clade of freshwater families with $62 \%$ of bootstraps. In addition, the marine family Xenotrichulidae and the subfamily Xenotrichulinae were also monophyletic (Fig. 2).

\section{Discussion}

The current analysis goes beyond classification; it is aimed at an elucidation of phylogenetic trends. In particular, trends in nervous-system structure in the Gastrotricha are revealed within the tree topology of the Macrodasyida. Basal genera often have multiple, separate nerve cords (4 in Dactylopodola), whereas more derived genera show partial fusion of nerve cords (4 fuse into 2 in Turbanella) or presumably complete fusion ( 2 in Thaumastodermatidae). The functional significance of this transition series is unknown; moreover, the trend is more ambiguous than supposed because other "intermediate" forms like Cephalodasys maximus show fusion ("schmelzen") of multiple (12) nerve cords, followed by subsequent bifurcation (Wiedermann, 1995). Other trends are also evident. For example, changes in reproductive biology (from hermaphroditic to parthenogenetic) seem to have occurred in chaetonotidan transitions from marine to freshwater biotopes.

This cladistic analysis also provides evidence that many characters used to define gastrotrichs in morphology-based phylogenies of extant Metazoa often are apomorphic for the phylum and, therefore, inappropriate. For example, Wallace et al. (1996) used the characters parthenogenesis, syncytial epidermis, and hypodermic impregnation in their analysis. The first two characters are known only in some chaetonotidans, and the third is unconfirmed except for the family Macrodasyidae and is unknown in basal taxa such as Dactylopodolidae. Backeljiau et al. (1993) incorrectly used eutely (found only in some chaetonotidans) and radial cleavage (gastrotrichs have aberrant bilateral cleavage) as characters defining gastrotrichs as a whole in their analysis. Finally, Zrzavy et al. (1998) used the character pseudocoelomate in their analysis, although all gastrotrichs are acoelomate.
Our cladistic analysis also provides a good test for molecular phylogenetic studies. Several earlier molecular studies have focused on derived taxa (Chaetonotus sp., Lepidodermella squamata) to resolve phylum-level relationships (Winnepenninckx et al., 1995; Littlewood et al., 1998; Zrzavy et al., 1998; Ruiz-Trillo et al., 1999). Such taxa are particularly easy to culture, but their utility as representative models is questionable. Lepidodermella squamata is especially controversial because it inhabits fresh water and is parthenogenetic-characteristics that are uncommon among chaetonotidans and virtually absent in macrodasyidans. The use of such derived forms should be avoided until the systematics of the Chaetonotida is better resolved.

Additionally, molecular systematics place the Gastrotricha in a variety of positions within the metazoan tree: as a sister group to either the Acanthocephala (Carranza et al., 1997), the Gnathostomulida (Littlewood et al., 1998), the Nematomorpha (Carranza et al., 1997), or the Platyhelminthes (Winnepenninckx et al., 1995). Other studies place the Gastrotricha basal to most of the Bilateria (Carranza et al., 1997), or to the Lophotrochozoa (Ruiz-Trillo et al., 1999) or the Spiralia (Littlewood et al., 1998). We, however, contend that the position of the Gastrotricha remains questionable until more primitive gastrotrich species are used, namely Neodasys or species of the Dactylopodolidae. These additions to the molecular data set would be a good test of tree strength and confirmation of their branching point from the remaining phyla.

A comprehensive and congruent classification of the phylum Gastrotricha is essential if its origin and phylogenetic significance are to be fully appreciated. The currently accepted classification is in dire need of revision, especially concerning the order Chaetonotida and the family Lepidodasyidae. At the same time, though, previous work on the systematics of the phylum has successfully navigated the treacheries of convergence and parallelism and displayed good phylogenetic congruence (Remane, 1933; Hummon, 1982; Ruppert, 1988). Yet, despite the rather small size of the phylum, the species are highly variable in particular characters (e.g., adhesive tubes, ciliary patterns, cuticular sculpture, reproductive anatomy), and recognition of plesiomorphy is often difficult.

Our study presents an evolutionary hypothesis for all Gastrotricha. Within this morphological framework, we now can address specific questions of relationships within and among individual gastrotrich taxa. For example, characters of the nervous system (i.e., number of nerve cords, fusion, distribution of neurotransmitters) can now be evaluated in light of the presumed primitiveness of the Dactylopodolidae. This framework also allows for a more careful selection of gastrotrich species representing the phylum as a whole in future global molecular studies. 


\section{Literature Cited}

Backeljiau, T., B. Winnepenninckx, and L. De Bruyn. 1993. Cladistic analysis of metazoan relationships: A reappraisal. Cladistics 9: 167-181.

Carranza, S., J. Baguñá, and M. Riutort. 1997. Are the Platyhelminthes a monophyletic primitive group? An assessment using $18 \mathrm{~S}$ rDNA sequences. Mol. Biol. Evol. 14: 485-497.

Hummon, W. D. 1982. Gastrotricha. Pp. 857-863 in Synopsis and Classification of Living Organisms. Vol. 1, S. P. Parker, ed. McGrawHill, New York.

Kisielewski, J. 1990. Origin and phylogenetic significance of freshwater psammic Gastrotricha. Stygologia 5(2): 87-92.

Littlewood, D. T. J., M. J. Telford, K. A. Clough, and K. Rohde. 1998. Gnathostomulida-an enigmatic metazoan phylum from both morphological and molecular perspectives. Mol. Phylogenet. Evol. 9(1): 72-79.

Lorenzen, S. 1985. Phylogenetic aspects of pseudocoelomate evolution. Pp. 210-223 in The Origins and Relationships of Lower Invertebrates. S. C. Morris, J. D. George, R. Gibson, and H. M. Platt, eds. Clarendon, Oxford.

Remane, A. 1933. Gastrotricha. Pp. 121-186 in Handbuch der Zoologie, II Band, 1 Hälfte. W. Kükenthal and T. Krumbach, eds. Walter de Gruyter, Berlin.

Rieger, R. M. 1976. Monociliated epidermal cells in Gastrotricha: significance for concepts of early metazoan evolution. Z. Zool. Syst. Evolutionsforsch. 14: 198-226.

Rieger, G. E., and R. M. Rieger. 1977. Comparative fine structure study of the gastrotrich cuticle and aspects of cuticle evolution within the aschelminthes. Z. Zool. Syst. Evolutionsforsch. 15: 81-124.

Ruiz-Trillo, I., M. Riutort, D. T. J. Littlewood, E. A. Hernieu, and J. Baguñá. 1999. Acoel flatworms: earliest extant bilaterian metazoans, not members of Platyhelmintes. Science 283: 1919-1923.

Ruppert, E. E. 1978. The reproductive system of gastrotrichs. II. Insemination in Macrodasys: a unique mode of sperm transfer in Metazoa. Zoomorphologie 89: 207-228.

Ruppert, E. E. 1982. Comparative ultrastructure of the gastrotrich pharynx and the evolution of myoepithelial foreguts in Aschelminthes. Zoomorphologie 99: 181-200.
Ruppert, E. E. 1988. Gastrotricha. Pp. 302-311 in Introduction to the Study of Meiofauna. R. P. Higgins and H. Thiel, eds. Smithsonian Institution Press, Washington, DC.

Ruppert, E. E. 1991. Gastrotricha. Pp. 41-109 in Microscopic Anatomy of Invertebrates. Volume 4: Aschelminthes. F. Harrison and E. E. Ruppert, eds. Wiley-Liss, New York.

Ruppert, E. E., and K. Shaw. 1977. The reproductive system of gastrotrichs. I. Introduction with morphological data for two new Dolichodasys species. Zool. Scr. 6: 185-195.

Schmidt-Rhaesa, A., T. Bartolomaeus, C. Lemburg, U. Ehlers, and J. R. Garey. 1998. The position of the Arthropoda in the phylogenetic system. J. Morph. 238: 263-285.

Swofford, D. L. 1999. PAUP*. Phylogenetic Analysis Using Parsimony (*and Other Methods). Verson 4.1.1b. Sinauer Associates, Sunderland, MA.

Travis, P. B. 1983. Ultrastructural study of body wall organization and Y-cell composition in the Gastrotricha. Z. Zool. Syst. Evolutionsforsch. 21: $52-68$.

Tyler, S., and G. E. Rieger. 1980. Adhesive organs of the Gastrotricha. I. Duo-gland organs. Zoomorphologie 95: 1-15.

Tyler, S., L. A. Melanson, and R. Rieger. 1980. Adhesive organs of the Gastrotricha. II. The organs of Neodasys. Zoomorphologie 95: 17-26.

Wallace, R. L., C. Ricci, and G. Melone. 1996. A cladistic analysis of pseudocoelomate (aschelminth) morphology. Invertebr. Biol. 115(2): 104-112.

Wiedermann, A. 1995. Zur Ultrastruktur des Nervensystems bei Cephalodasys maximus (Macrodasyida Gastrotricha). Microfauna Mar. 10: 173-233.

Winnepenninckx, B., T. Backelijau, L. Y. Mackey, J. M. Brooks, R. De Wachter, S. Kumar, and J. Garey. 1995. 18S rRNA data indicate that aschelminthes are polyphyletic in origin and consist of at least three distinct clades. Mol. Biol. Evol. 12(6): 1132-1137.

Zrzavy, J., S. Mihulka, P. Kepka, and A. Bezdka. 1998. Phylogeny of the Metazoa based on morphological and 18S ribosomal DNA evidence. Cladistics 14: 249-285. 
http://www.jstor.org

\title{
LINKED CITATIONS \\ - Page 1 of 1 -
}

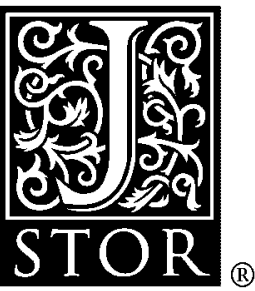

You have printed the following article:

Phylogeny of Gastrotricha: A Morphology-Based Framework of Gastrotrich Relationships

Rick Hochberg; Marianne K. Litvaitis

Biological Bulletin, Vol. 198, No. 2. (Apr., 2000), pp. 299-305.

Stable URL:

http://links.jstor.org/sici?sici=0006-3185\%28200004\%29198\%3A2\%3C299\%3APOGAMF\%3E2.0.CO\%3B2-X

This article references the following linked citations. If you are trying to access articles from an off-campus location, you may be required to first logon via your library web site to access JSTOR. Please visit your library's website or contact a librarian to learn about options for remote access to JSTOR.

\section{Literature Cited}

\author{
Acoel Flatworms: Earliest Extant Bilaterian Metazoans, Not Members of Platyhelminthes \\ Iñaki Ruiz-Trillo; Marta Riutort; D. Timothy J. Littlewood; Elisabeth A. Herniou; Jaume Baguñà \\ Science, New Series, Vol. 283, No. 5409. (Mar. 19, 1999), pp. 1919-1923. \\ Stable URL: \\ http://links.jstor.org/sici?sici=0036-8075\%2819990319\%293\%3A283\%3A5409\%3C1919\%3AAFEEBM\%3E2.0.CO\%3B2-6
}

